\title{
Potential of Sweet Basil (Ocimum basilicum) as a Hepatoprotector Agent for Liver Injury Related to Drugs
}

\author{
Dede Renovaldi ${ }^{1}$, Abdul Khalik Adam² \\ 1) Department of Biomedic, Faculty of Medicine and Health, Universitas Muhammadiyah Jakarta \\ 2) Medical Study Program, Faculty of Medicine, Universitas Muhammadiyah Purwokerto \\ *Corresponding author: dede.renovaldi@gmail.com
}

\begin{abstract}
Background: The use of drugs is one of the most common causes of liver injury, because the liver is the main organ that metabolizes drugs. Little is currently done if there is a liver injury due to the hepatotoxic side effects of a drug. Herbal plants have active natural compounds that have pharmacological effects so they are widely used as alternative treatments. Sweet basil (Ocimum basilicum) is one of the most cultivated plants in Asia. Studies on the use of Ocimum basilicum in medicine have been carried out, one of which is the hepatoprotector effect. The objective is to investigate the potential of Ocimum basilicum as a hepatoprotective agent for liver injury associated with drugs. Literature searching was conducted as a method through PubMed, Science Direct and Embase. Results: Studies indicate that Ocimum basilicum is rich in high antioxidant content (flavonoids, saponins, tannins, sterols, triterpenes, and rosmaniric acid) capable of providing hepatoprotector effects by helping the regeneration process of hepatocyte cells that are damaged by hepatotoxic agents and significantly decreasing liver damage biomarkers. The purpose of this review is to explain the potential of Ocimum basilicum as a hepatoprotective agent for liver injury associated with drugs. Conclusion: Ocimum basilicum has high potential in its utilization as a hepatoprotector against liver injury mainly related to the consumption of drugs that have hepatotoxic effects.
\end{abstract}

Keywords: Ocimum basilicum, Hepatoprotector, Herbs, Antioxidant.

\section{INTRODUCTION}

The liver is an important organ that regulates the internal environment of the human body, especially in regulating nutrients, metabolism of carbohydrates, proteins, and fats so that the impairment of liver function will significantly affect the body's metabolic balance. Injury to the liver can be caused by infection or non-infection. One primary cause of non-infectious liver injury is the consumption of drugs. Medications are known to be a major cause of liver injury. More than 900 types of drugs are reported to cause injury to the liver. Several types of drugs can induce liver disease such as acute-dose dependent liver damage, but it can also be found in acute fat infiltration, cholestatic jaundice, liver granuloma, active chronic hepatitis, cirrhosis of the liver, liver tumors, etc. Liver injuries caused by drugs are responsible for $5 \%$ of all hospitalizations and $50 \%$ of all acute liver failure. More than 75 percent of cases of idiosyncratic drug reactions cause increased rates of liver transplantation and death (1). Hepatotoxic 
effects also often cause interruption of antituberculosis drug treatment regimens (isoniazid, rifampicin, pyrazinamide), thus inhibiting the healing process of patients with tuberculosis (2).

The WHO survey shows that $80 \%$ of the population in developing countries use herbal medicines for their health needs. Recognizing the importance of plants in the discovery of new and safer therapeutic agents, herbal screening for pharmacological activities and phytochemical constituents is one area of active research throughout the world today (3). Sweet Basil (Ocimum basilicum) is a plant that is often consumed by Indonesian people and is thought to have many functions in the treatment of various diseases. Basil is rich in antioxidants in the form of eugenol, flavonoids and ursal acid which functions as a free radical scavenger in human body (4).

The Ocimum species contain a large number of antioxidants, vitamin $\mathrm{C}$, vitamin E, flavonoids, and carotenoids. The presence of these active compounds provides protection against free radicals induced by oxidative damage to cellular components that involve the formation of Reactive Oxygen Species (ROS) molecules. Ocimum basilicum is one of the Ocimum species that has the greatest antioxidant activity compared to other Ocimum species (5). Ocimum basillicum is known to have compounds with high antioxidant activity that can prevent the activity of oxidative stress on cells. Ocimum basillicum is a source of flavonoids, which have been shown to have various biological properties related to antioxidant mechanisms in acting as hepatoprotector (6). Based on this phenomenon and data, the aim of this review is to investigate the potential of
Ocimum basilicum as a hepatoprotective agent for liver injury associated with drugs.

The combined inquiry utilizing PUBMED, Science Direct and EMBASE was led on January 2020. The studies selected based on the titles, abstract, and duplicates screened. The full-text articles were assessed dependently on qualification standards that had similar topics and discussions.

\section{LITERATURE REVIEW \\ Drug Induced Liver Injury (DILI)}

DILI accounts for $7 \%$ of the total reported drug side effects, and about $30 \%$ of fulminant liver failure. DILI has replaced the hepatitis virus as a cause of acute liver failure. There are more than 700 drugs with hepatotoxicity that have been reported and approved for use in the United States. DILI can result from direct toxicity from major compounds, metabolites, or from an immunological mediating response that can affect hepatocytes, bile epithelial cells, and / or hepatic vascularization (7).

Damaging free radicals can cause hepatocyte necrosis in the most peripheral zones of the liver arterioles, which are the greatest metabolism and the least antioxidant detoxification capacity. In hypersensitivity reactions, immunogenic drugs or their metabolites may be free or covalently bound to liver proteins, forming haptens, or neoantigens. Cytotoxic responses will react to remove tumor necrosis factor-a (TNFa), interleukin-12 and IFN to trigger cell death / hepatocellular apoptosis. The metabolic idiosyncratic reaction can result from genetic variations or obtained in biotransformation drugs, by synthesis or slow detoxification of hepatotoxic metabolites. Metabolic idiosyncratic reactions may have very variable latent 
periods, but they recur at some time after reexposure (8).

In many prospective studies, it was found that antimicrobials, including antibiotics and anti-tuberculosis agents, accounted for about $46 \%$ of all DILI cases. In addition, among the top 10 drugs in the DILI registry in the US, are antibiotics (except Diclofenac). The most common drugs associated with liver injury in at least three prospective studies are amoxicillinclavunate, isoniazid, rifampicin + isoniazid + pyrazinamide, flutamide, and ibuprofen (9).

\section{Sweet Basil (Ocimum Basilicum)}

Ocimum basilicum is commonly known as sweet basil, belonging to the genus Ocimum from the family Lamiaceae. Ocimum (from the Greek ouzo for smell) is suitable for this genus because its various species are known for their distinctive strong aroma (3). Sweet basil is one of the spices used frequently (Lamiaceae family), known to have strong antioxidant and antimicrobial activity due to phenolic acids and aromatic compounds. This plant grows every year in Asia, India, Africa and other temperate regions throughout the world. Traditionally, every part of the plant is used as a medicine to treat headaches, coughs, diarrhea, constipation, impaired kidney function, and digestive problems. Vegetable basil plants have moderate macro and micro nutritional value including protein $(3.15 \mathrm{~g} / 100 \mathrm{~g})$, fat $(0.64 \mathrm{~g} / 100 \mathrm{~g})$, energy ( $23 \mathrm{Kcal})$, Vitamin C (18 mg / 100 g), Vitamin E (0.80 mg / $100 \mathrm{~g})$, Vitamin A $(5275 \mathrm{IU})$, Vitamin K (414.8 $\mathrm{mcg})$, Calcium (177 mg / 100 g), Iron (3.17 mg / 100g), Potassium (295 mg / $100 \mathrm{~g}$ ), Magnesium (64 mg / 100g), and Sodium (4 $\mathrm{mg} / 100 \mathrm{~g})(10)$.

\section{Hepatoprotector Activities of Ocimum Basilicum}

Studies on the hepatoprotective effect of Ocimum basilicum have been extensively studied. Research conducted by Meera et al. (2009) showed that the administration of Ocimum basilicum extract significantly prevented liver damage which was characterized by a decrease in serum enzyme levels of ALT, AST, ALP, and GGT in the sample groups induced by $\mathrm{H} 2 \mathrm{O} 2$ and CCL4 as hepatotoxic agents (4). In accordance with this finding, Yacout et al. (2012) also found a protective effect given basil extract (Ocimum basilicum) in the treatment subject group which was marked by a significant decrease in serum transaminase (ALT and AST) activity compared to the group of subjects given CCL4 (6).

A study conducted by Surana and Jain (2010) states that ethanol extract from Ocimum species can reduce elevated levels of the ALT and AST enzymes and showed protection activity to the structural integrity of hepatocyte cell membranes and regeneration of damaged liver cells (11). Likewise, a study conducted by Mahboub and Arisha (2015) found that the administration of Ocimum basilicum extract improved the histological structure repair of liver cells damaged by induction from diazinon and showed an increase in liver function (12).

These findings implicated the effectiveness of Ocimum basilicum in preventing liver damage and helping repairment of hepatocyte cells due to the hepatotoxic agents. This is predicted by the presence of phytochemical compounds that have high antioxidant activity that able to prevent the oxidative stress activity on liver cells. Oxidative stress is one of the main pathways of hepatotoxic agents in affecting 
damage to hepatocyte cells. Antioxidants are substances that can prevent oxidation processes in cells due to toxins and free radicals. Ocimum basilicum is source of flavonoids and other compounds, which have been shown to have various biological properties associated with antioxidant mechanisms (13). Sakr et al. (2011) concluded that the hepatoprotective effect of Ocimum basilicum might occur due to the antioxidant activity of flavonoids in it (14).

The Ocimum species contain a large number of antioxidants, vitamin $\mathrm{C}$, vitamin E, flavonoids, and carotenoids. The existence of these active compounds provides protection against oxidative stress and free radicals induced by hepatotoxic agents that cause oxidative damage to cellular components and the formation of Reactive Oxygen Species (ROS) molecules. Ocimum basilicum is one of the Ocimum species that has the greatest antioxidant activity compared to other Ocimum species (5). Furthermore, a study conducted by Belgies et al. (2015) states that the protective effect of Ocimum basilicum has a strong relationship with the antioxidant activity of flavonoids, saponins, tannins, sterols, and triterpenes as well as the resistance activity of superoxide radicals and nitric oxide. In addition, other findings show that administration of Ocimum basilicum extracts triggers the formation of structural integrity in hepatocyte cell membranes and the regeneration of damaged liver cells (15).

In addition to flavonoid content, Ocimum basilicum is also rich in rosmaniric acid which was reported to had a hepatoprotective effect by preventing hepatocyte damage and fibrosis tissue formation. Research conducted by Mahmood and Sidik (2005) states that
Ocimum basilicum has a hepatoprotective and antifibrotic effect that is associated with the antioxidant activity of rosmaniric acid. Rosmaniric acid decreases the conversion of liver stellate cells to myofibroblast and decreases gene expression of extracellular matrix components needed in fibrosis formation (16).

\section{CONCLUSION}

Ocimum basilicum is one of the Lamiaceae family which has the highest antioxidant content compared to other ocimum species. This review presents the potential of hepatoprotective effect by Ocimum basilicum on various toxic agents by drugs on the liver, especially related to the consumption of drugs that have hepatotoxic effects. The potential of hepatoprotective by Ocimum basilicum is predicted through the protection of liver cells by the activity of antioxidant compounds. Ocimum basilicum contains various antioxidant compounds that play a role in the protection of hepatocyte cells including flavonoids, saponins, tannins, sterols, triterpenes, and rosmaniric acid. The results of this review imply the potential use of Ocimum basilicum as a hepatoprotective agent for liver damage, especially caused by drugs.

\section{ACKNOWLEDGMENT}

Authors acknowledge the immense help received from the scholars whose articles are cited and included in references of this manuscript. The authors are also grateful to authors / editors / publishers of all those articles, journals and books from where the literature for this article has been reviewed and discussed. 


\section{CONFLICT OF INTEREST}

There is no conflict of interest among the authors.

\section{REFERENCE}

1. Pandit A, Sachdeva T, Bafna P. Drug-induced hepatotoxicity: A review. J Appl Pharm Sci. 2012;2(5):233-43.

2. Wang P, Pradhan K, Zhong X, Ma X. Isoniazid metabolism and hepatotoxicity. Acta Pharm Sin B. 2016;6(5):384-92.

3. Khair-ul-Bariyah S, Ahmed D, Ikram M. Ocimum Basilicum: A Review on Phytochemical and Pharmacological Studies. Pakistan J Chem. 2012;2(2):78-85.

4. Meera R, Devi P, Kameswari B, Madhumitha B, Merlin NJ. Antioxidant and hepatoprotective activities of Ocimum basilicum Linn . and Trigonella foenum-graecum Linn . against $\mathrm{H} 2 \mathrm{O} 2$ and $\mathrm{CCl} 4$ induced hepatotoxicity in goat liver. 2009;47(July):584-90.

5. Pandey AK, Singh P, Tripathi NN. Chemistry and bioactivities of essential oils of some Ocimum species: an overview. Asian Pac J Trop Biomed. 2014;4(9):682-94.

6. Galila AY, Nihal ME, Eman FEA. Hepatoprotective effect of basil (Ocimum basilicum L.) on CCl4induced liver fibrosis in rats. African J Biotechnol. 2012;11(90):1570211.

7. Saukkonen JJ, Cohn DL, Jasmer RM, Schenker S, Jereb JA, Nolan $\mathrm{CM}$, et al. American Thoracic Society Documents An Official ATS Statement: Hepatotoxicity of Antituberculosis Therapy.
8. Moudgil V, Redhu D, Dhanda S, Singh J. A review of molecular mechanisms in the development of hepatocellular carcinoma by aflatoxin and hepatitis B and C viruses. J Environ Pathol Toxicol Oncol. 2013;32(2):165-75.

9. Björnsson ES. Hepatotoxicity by drugs: The most common implicated agents. Int J Mol Sci. 2016;17(2).

10. Falowo AB, Mukumbo FE, Idamokoro EM, Afolayan AJ, Muchenje V. Phytochemical Constituents and Antioxidant Activity of Sweet Basil (Ocimum basilicum L.) Essential Oil on Ground Beef from Boran and Nguni Cattle. Int J Food Sci. 2019;2019.

11. Surana V, Jain D. Protective Effect of Ocimum Gratissimum Against Carbon Tetrachloride in Rats. Pharmacologyonline. 2010;2:11119.

12. Print I, Online I, Mahboub FA, Arisha SM. Hepatoprotective effect of Ocimum basilicum extract against the toxicity of diazinon in albino rats : Histopathological and immunohistochemical evaluation. World J Pharm Sci. 2015;3(5):7909.

13. Purushothaman B, Prasannasrinivasan R, Suganthi P, Ranganathan B, Gimbun J, Shanmugam K. A comprehensive review on Ocimum basilicum. J Nat Remedies. 2018;18(3):71-85.

14. Sakr SA, El-Abd SF, Osman M, Kandil AM, Helmy MS. Ameliorative Effect of Aqueous Leave Extract of Ocimum basilicum on Ccl4 - Induced Hepatotoxicity and Apoptosis in Albino Rats. J Am Sci. 2011;7(8):116-27. 
15. Belgies AA, Mohamed AH, Ali SA, Afaf IA. Hepatoprotective Activity of Ethanol Extract of Ocimmum basillicum against $\mathrm{CCl} 4$-induced Hepatotoxicity in Albino Rats. J Nat Med Sci. 2015;16(2):11-8.

16. Mahboub FA, Arisha SM. Hepatoprotective effect of Ocimum basilicum extract against the toxicity of diazinon in albino rats : Histopathological and immunohistochemical evaluation. World J Pharm Sci. 2015;3(5):7909. 